\title{
Acidimicrobium ferrooxidans gen. nov., sp. nov.: mixed-culture ferrous iron oxidation with Sulfobacillus species
}

\author{
Darren A. Clark and Paul R. Norris \\ Author for correspondence: Paul R. Norris. Tel: +44 1203 523733. Fax: +44 1203523701. \\ e-mail:pn@dna.bio.warwick.ac.uk
}

Department of Biological Sciences, University of Warwick, Coventry

CV4 7AL, UK

\begin{abstract}
A new species of ferrous-iron-oxidizing, moderately thermophilic, acidophilic bacteria, Acidimicrobium ferrooxidans, has been described. Two isolates of the species differed only in the tendency of one, previously known as strain TH3, to grow in filaments. The chromosomal DNA base composition is between 67 and $69 \mathrm{~mol} \% \mathrm{G}+\mathrm{C}$. The capacity of this species to fix $\mathrm{CO}_{2}$ from air was greater than that of iron-oxidizing thermoacidophiles of the genus Sulfobacillus, which required an enhanced $\mathrm{CO}_{2}$ concentration for optimum autotrophic growth. Under air, ferrous iron oxidation in mixed cultures of A. ferrooxidans with either Sulfobacillus thermosulfidooxidans or Sulfobacillus acidophilus was more extensive than in pure cultures of these three strains. The greater part of ferrous iron oxidation in mixed cultures probably resulted from activity of the Sulfobacillus species, which possess a greater tolerance of ferric iron, and which presumably grew mixotrophically utilizing organic compounds from A. ferrooxidans.
\end{abstract}

Keywords: Acidimicrobium ferrooxidans, iron oxidation, Sulfobacillus

\section{INTRODUCTION}

A moderately thermophilic, ferrous-iron-oxidizing acidophile isolated from a copper leaching dump was noticeably smaller than physiologically similar bacteria isolated from a test copper leaching system and a hot spring (Brierley, 1978). This bacterium, strain TH3, has received little study in comparison to the larger organisms, which have become recognized as species of Sulfobacillus (Golovacheva \& Karavaiko, 1979; Karavaiko et al., 1988; Norris et al., 1996). Sulfobacillus thermosulfidooxidans (strain TH1) and strain TH3 appeared to have similar requirements for yeast extract or cysteine for growth on ferrous iron (Norris et al., 1980). Autotrophic growth of $S$. thermosulfidooxidans strains was subsequently demonstrated (Marsh \& Norris, 1983; Wood \& Kelly, 1983), whereas the evidence for autotrophic growth of strain TH3 was less convincing because of some difficulty in consistently demonstrating the relatively little ferrous iron oxidation that occurred in the absence of yeast extract (Norris \& Barr, 1985). The $16 \mathrm{~S}$ rRNA sequence of strain TH3 indicated an affiliation with the high mol \% G + C subdivision of the Gram-positive bacteria (Lane et al., 1992).

Another strain of the TH3 type is described in this paper. The source was a pyrite enrichment culture grown at
$48{ }^{\circ} \mathrm{C}$ under air (Norris \& Owen, 1993). Rapid oxidation of pyrite by this entichment culture during autotrophic growth in the absence of an enhanced $\mathrm{CO}_{2}$ concentration seemed to be due to activity of a previously undescribed organism. Optimum autotrophic growth of Sulfobacillus strains on ferrous iron had been obtained only when cultures were supplemented with $\mathrm{CO}_{2}$ (Marsh \& Norris, 1983; Wood \& Kelly, 1983), and pyrite oxidation by Sulfobacillus strains was very slow during growth under air (Norris, 1989; Norris \& Owen, 1993). This paper indicates the probable role of strain TH3-like bacteria in promoting oxidation of ferrous iron and mineral sulphides by Sulfobacillus species in the absence of an enhanced $\mathrm{CO}_{2}$ concentration or organic supplements.

\section{METHODS}

Bacterial strains. Sulfobacillus thermosulfidooxidans (strains LM1 and BC1), Sulfobacillus acidopbilus (strain NAL), strain TH3, and their sources, are described in the accompanying paper (Norris et al., 1996). The designation TH3 was used previously (Brierley, 1978; Norris et al., 1980) for a strain which was not retained in laboratory culture. The available strain TH3 appeared very similar to the original strain (Norris \& Barr, 1985), and both strains came from the same site.

Isolation of novel strains. A pyrite enrichment culture that was established with a sample from an Icelandic geothermal site 
(Norris \& Owen, 1993) was used to inoculate a ferrous-ironcontaining medium. A culture was obtained which grew autotrophically at $48{ }^{\circ} \mathrm{C}$ in the absence of an enhanced $\mathrm{CO}_{2}$ concentration. A Percoll gradient (Pertoft et al., 1978) was used in an attempt to separate morphologically distinct bacteria that were observed in the culture, because of difficulty in obtaining colonies on solid medium. Bacteria were harvested by centrifugation, washed and resuspended in dilute $\mathrm{H}_{2} \mathrm{SO}_{4}(\mathrm{pH} 2)$. Percoll (colloidal polyvinylpyrrolidone-coated silica; Sigma) was adjusted from $\mathrm{pH} 8.9$ to 5.5 , the lowest $\mathrm{pH}$ that could be used without gelling, by dilution with $0.2 \mathrm{M}$ glycine buffer $(\mathrm{pH} 2.6)$ to give $71 \%(\mathrm{v} / \mathrm{v})$ Percoll. A range of concentrations was tested to determine this optimum Percoll concentration for separation of the bacterial types in the mixed culture. Cell suspension $(200 \mu \mathrm{l})$ was loaded onto Percoll $(8 \mathrm{ml})$ and a gradient was formed by centrifugation at $11500 \mathrm{~g}$ for $25 \mathrm{~min}$. The density gradient was measured using standard marker beads of known density (Sigma). Samples were removed at different levels from gradients using hypodermic needles and centrifuged. Cell pellets were washed before bacteria were examined by microscopy or plated on solid medium.

Culture conditions. The media for growth on ferrous iron $(50 \mathrm{mM})$, sulphur $\left(5 \mathrm{~g} \mathrm{l}^{-1}\right)$ and yeast extract $\left(0 \cdot 25 \mathrm{~g}^{-1}\right)$ have been described (Norris $e t$ al., 1996). Cultures were gassed with air or with $5 \%(\mathrm{v} / \mathrm{v}) \mathrm{CO}_{2}$ in air, as indicated. Where indicated, glucose $(1 \mathrm{mM})$ was included in the ferrous-iron-containing medium. All cultures were grown at $48^{\circ} \mathrm{C}$, except for one experiment where growth at different temperatures was examined.

Solid medium. The liquid mineral salts medium was used with a reduction in the phosphate concentration $\left(\mathrm{K}_{2} \mathrm{HPO}_{4}\right.$, $0.01 \mathrm{~g} \mathrm{l}^{-1}$ ), and addition of $20 \mathrm{mM} \mathrm{FeSO} \cdot 7 \mathrm{H}_{2} \mathrm{O}$ and $0.4 \%$ (w/v) Phytagel (Sigma). Plates were made by mixing equal volumes of solidifying agent in distilled water to the mineral salts solution ( $\mathrm{pH} \mathrm{2 \cdot 2)}$ as they cooled after separate sterilization. The medium was also supplemented with either tetrathionate $\left(\mathrm{K}_{2} \mathrm{~S}_{4} \mathrm{O}_{6}, 0 \cdot 15 \mathrm{~g} \mathrm{l}^{-1}\right)$ as the source of reduced sulphur required for autotrophic growth on ferrous iron or with yeast extract $\left(0 \cdot 2 \mathrm{~g} \mathrm{l}^{-1}\right)$. Plates were incubated at $48^{\circ} \mathrm{C}$ under air.

Microscopy, growth assays, electrophoresis, DNA preparation and DNA mol \% $\mathbf{G}+\mathbf{C}$ analysis. Methods were as described by Norris et al. (1996). Protein was determined by the Lowry method with BSA as standard.

\section{RESULTS}

\section{Isolation of novel strains}

An enrichment culture with the capacity for rapid and extensive oxidation of $50 \mathrm{mM}$ ferrous iron at $48^{\circ} \mathrm{C}$, in the absence of an enhanced $\mathrm{CO}_{2}$ concentration, was established. Initial attempts to grow ferrous-iron-oxidizing bacteria from the culture on solid medium resulted in development of colonies of Sulfobacillus-like bacteria. A pure culture, designated strain $\mathrm{ICH}$, was obtained using plates containing ferrous iron and yeast extract. This isolate was found, by comparative gel electrophoresis of whole-cell proteins (data not shown) and determination of chromosomal DNA G +C content (Table 1), to be a strain of Sulfobacillus thermosulfidooxidans. In contrast to the enrichment culture, strain ICH grew autotrophically very poorly on ferrous iron in the absence of an enhanced $\mathrm{CO}_{2}$ concentration (data not shown).
Table 1. Chromosomal DNA base composition of moderately thermophilic, ferrous-iron-oxidizing acidophiles

\begin{tabular}{|ccc|}
\hline Strain & \multicolumn{2}{c|}{ Mol\% G+C } \\
\cline { 2 - 3 } & This study & $\begin{array}{c}\text { Other } \\
\text { values* }\end{array}$ \\
\hline ICP & $67 \cdot 3$ & \\
TH3 & $68 \cdot 0$ & $68 \cdot 5^{a}, 67 \cdot 7^{b}$ \\
ICH & $47 \cdot 5$ & \\
BC1 & $48 \cdot 2$ & $50 \cdot 4^{a}, 48 \cdot 6^{b}$ \\
NAL & $54 \cdot 9$ & $56 \cdot 2^{b}$ \\
\hline
\end{tabular}

$* a$, Harrison (1986); $b$, Norris et al. (1996).

A Percoll gradient was used in an attempt to separate the Sulfobacillus-like bacteria and smaller organisms that were observed in the enrichment culture by microscopy. An upper, diffuse band corresponding to a buoyant density of about 1.08-1.09 $\mathrm{g} \mathrm{ml}^{-1}$ contained Sulfobacillus-like bacteria (Fig. 1). The lower band, corresponding to a buoyant density of about $1.12 \mathrm{~g} \mathrm{ml}^{-1}$, contained mostly the smaller bacteria. The separation appeared efficient, but there were a few Sulfobacillus-like bacteria in the lower band (one is shown in thin section in the bottom-right of the electron micrograph of lower-band bacteria in Fig. 1). This precluded simple removal of a sample from the lower band to establish a pure culture of the relatively small bacteria.

Small colonies of the relatively small bacteria were obtained after autotrophic growth on solid medium under air when samples were plated from a culture which had been maintained through a continuous sequence of serial cultures on ferrous iron under air for several weeks (35 serial cultures). It is not known if this period of culturing led to some adaptation that was significant in finally obtaining single colony development, or whether there was an unrelated reason for an earlier lack of success in plating. The small organism was designated strain ICP. It was also obtained from the same enrichment culture by D. Barrie Johnson (University of Wales, Bangor; personal communication) using an overlay plating technique (Johnson \& McGinness, 1991) that allows more consistent colony development of ferrous iron-oxidizing acidophiles.

\section{Morphology}

The contrast in morphology between strain ICP and Sulfobacillus species was evident from comparison of the two types separated on a Percoll gradient (Fig. 1) and from electron micrographs of thin sections of cells from the ferrous iron enrichment culture containing both types (Fig. 2a). Strain ICP was narrower (width $0.4 \mu \mathrm{m}$ ) than the Sulfobacillus-like cells, which showed the typical morphology of autotrophically growing $S$. thermosulfidooxidans 

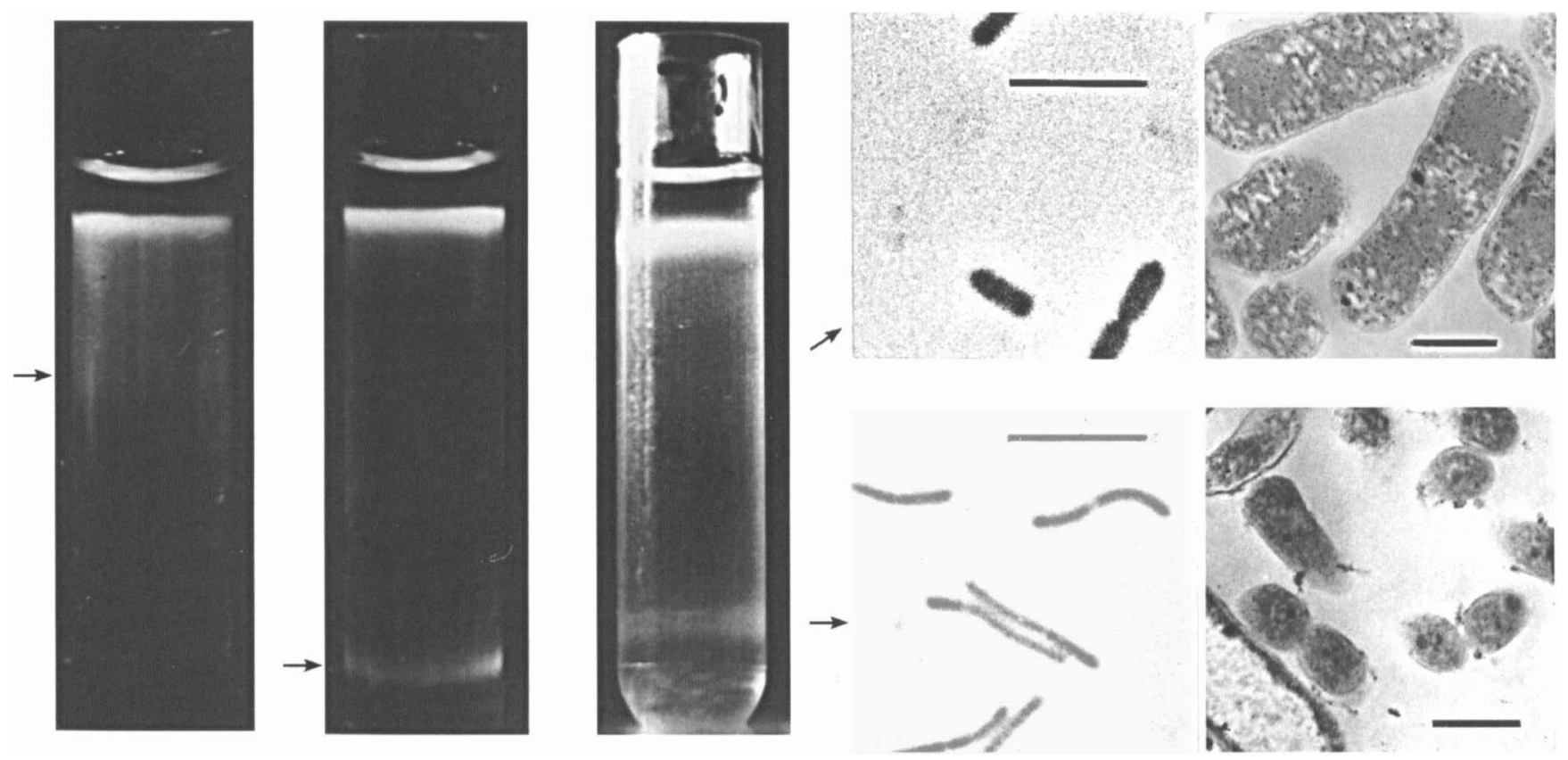

Fig. 1. Percoll gradient buoyant-density separation of bacteria from a mixed culture of ferrous-iron-oxidizing moderate thermophiles. Three gradients show the distribution of bacteria from pure cultures of Sulfobacillus thermosulfidooxidans strain ICH (left), and strain ICP (centre), and from the natural mixed culture from which these strains were isolated (right). Arrows indicate the zones of the pure culture gradients where the highest concentration of bacteria were found, and mark two levels in the mixed culture gradient from which samples were taken and examined by light microscopy (bars, $5 \mu \mathrm{m}$ ) and electron microscopy (bars, $0.5 \mu \mathrm{m}$ ).
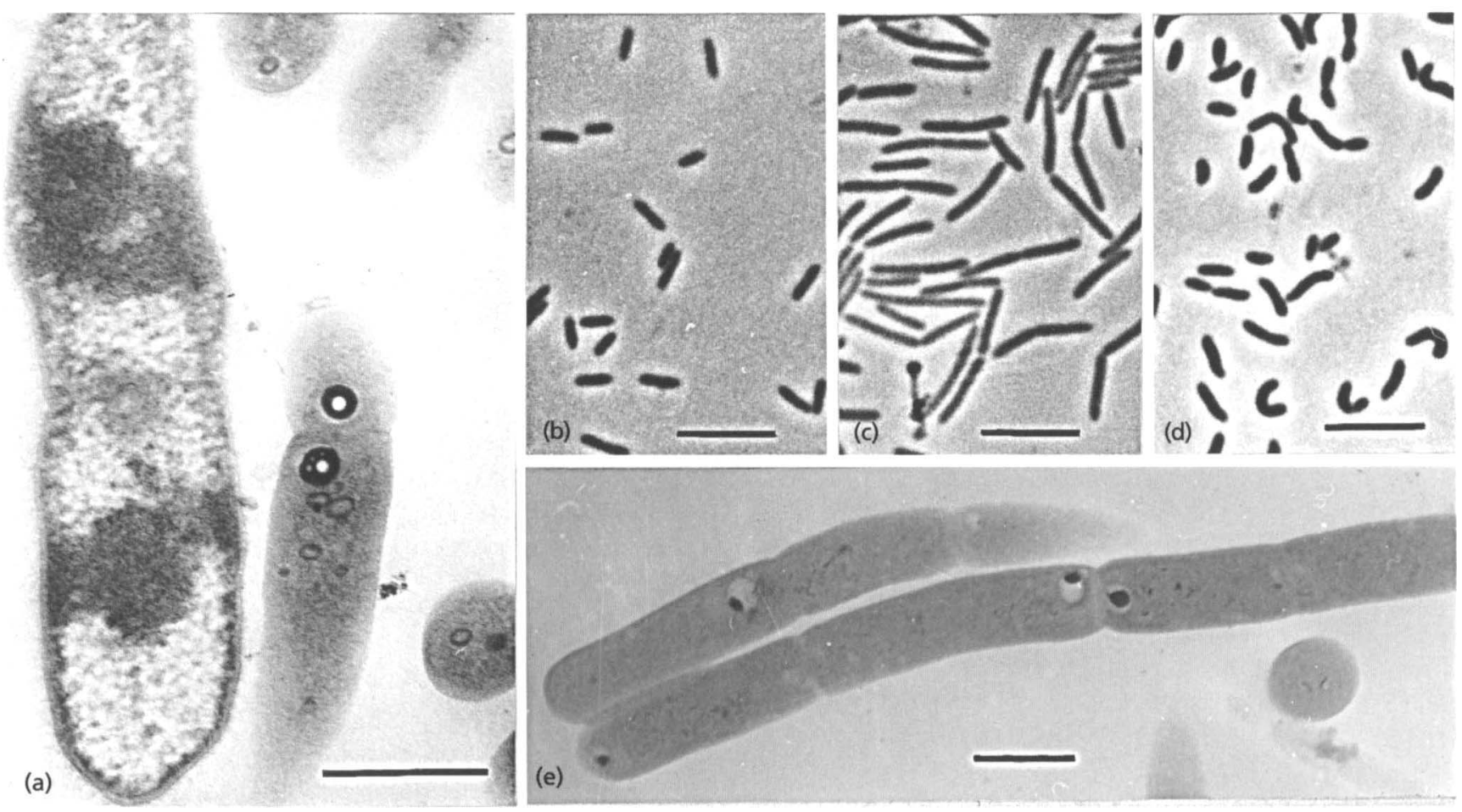

Fig. 2. Morphology of ferrous-iron-oxidizing moderate thermophiles. (a) Thin sections of a relatively large Sulfobacilluslike bacterium and smaller organisms in the natural mixed culture (bar, $0.5 \mu \mathrm{m})$. (b-d) Light microscopy of strain ICP grown autotrophically on ferrous iron (b), on ferrous iron in the presence of yeast extract (c), and heterotrophically on yeast extract (d) (bars, $5 \mu \mathrm{m}$ ). (e) Thin sections of strain TH3 grown on ferrous iron and yeast extract (bar, $0.5 \mu \mathrm{m})$. 


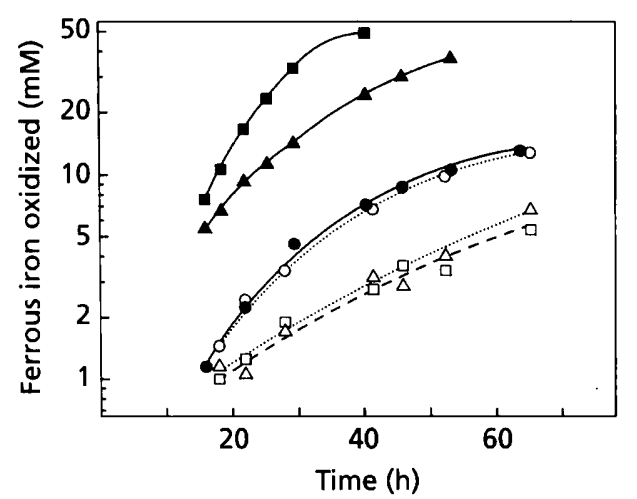

Fig. 3. Ferrous iron oxidation during autotrophic growth of moderate thermophiles in cultures gassed with air (open symbols; $10 \%, v / v$, inoculum from cultures grown under air) and in cultures gassed with $5 \%(\mathrm{v} / \mathrm{v}) \mathrm{CO}_{2}$ in air (solid symbols; $5 \%$, v/v, inoculum from cultures grown with $\mathrm{CO}_{2}$ supplementation). $\square, \square, S$. thermosulfidooxidans strain LM1; $\triangle, \triangle, S$. acidophilus strain NAL; $O$, , strain ICP.

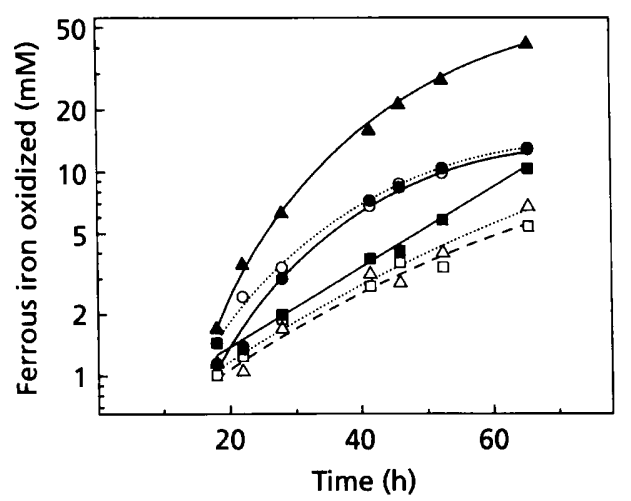

Fig. 4. Ferrous iron oxidation during growth of moderate thermophiles in cultures gassed with air (all cultures) and supplemented with $1 \mathrm{mM}$ glucose (solid symbols only). $\square, \square, S$. thermosulfidooxidans strain LM1; $\triangle, \Delta, S$. acidophilus strain NAL; $O$, strain ICP. Inocula $(10 \%$, v/v) were from cultures grown autotrophically under air.

(Norris et al., 1996). In contrast to $S$. thermosulfidooxidans but in common with Sulfobacillus acidophilus (Norris $e t$ al., 1996), strain ICP did not greatly increase in size when switched from autotrophic (Fig. 2b) to heterotrophic growth (Fig. 2d), but cells were slightly more elongated during growth on ferrous iron and yeast extract (Fig. 2c). Strain ICP could be distinguished from strain TH3 (Fig. 2e) only by the latter's frequent filamentous habit.

\section{DNA base composition}

The high mol $\% \mathrm{G}+\mathrm{C}$ content of DNA of strain TH3 (Norris et al., 1996) was matched by that of strain ICP at 67-68 $\mathrm{mol} \%$.

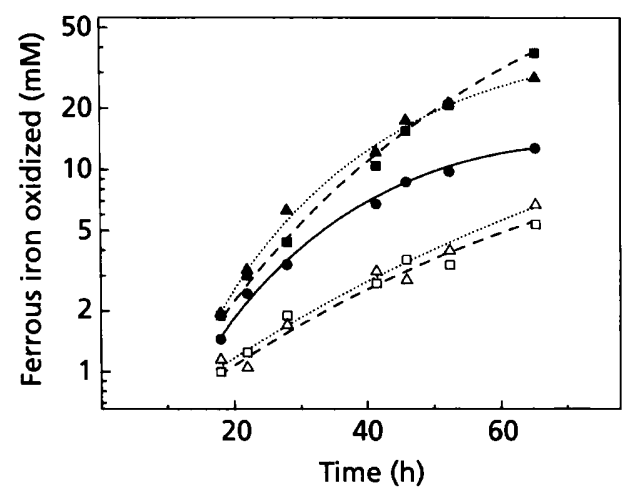

Fig. 5. Ferrous iron oxidation during growth of moderate thermophiles in pure and mixed cultures gassed with air. $\square, \square$, $S$. thermosulfidooxidans strain LM1 in pure culture $(\square)$ and with strain ICP $(\square) ; \triangle, \Delta, S$. acidophilus strain NAL in pure culture $(\triangle)$ and with strain ICP $(\Delta)$; 0 , strain ICP in pure culture. Inocula were $10 \%(\mathrm{v} / \mathrm{v})$ for pure cultures and $5 \%(\mathrm{v} / \mathrm{v})$ for each strain to establish the mixed cultures.

\section{Whole-cell protein electrophoresis}

Strain TH3 was readily distinguishable from other moderately thermophilic iron-oxidizing species on the basis of electrophoretic protein profiles (Norris et al., 1996). The protein profiles of strains TH3 and ICP were essentially identical (not shown).

\section{Growth on ferrous iron}

In the absence of an enhanced $\mathrm{CO}_{2}$ concentration, growthassociated ferrous iron oxidation by strain ICP (Fig. 3) was superior to that of two species of Sulfobacillus, $S$. thermosulfidooxidans (strain LM1) and S. acidopbilus (strain NAL). The relatively poor growth-associated ferrous iron oxidation by Sulfobacillus species was stimulated by supplementing culture aeration with $\mathrm{CO}_{2}$ (Fig. 3) or supplementing the medium with glucose (Fig. 4), although glucose had a limited effect on strain LM1. Ferrous iron oxidation during growth of strain ICP was not influenced by either supplementation (Figs 3 and 4). Iron oxidation during growth of strain ICP in mixed culture with either Sulfobacillus species (strain NAL or strain LM1) under air was approximately equivalent to that during growth of $\mathrm{CO}_{2}$-supplemented cultures of Sulfobacillus species, and far more extensive than that by strain ICP (Fig. 5). Growth of strains TH3 and ICP on ferrous iron was similar (Norris et al., 1996) and strain TH3 substituted for strain ICP with similar effect in mixed culture with Sulfobacillus species under air (data not shown).

\section{Heterotrophic growth}

The maximum doubling time for growth of strain TH3 (data not shown) and of strain ICP on yeast extract at the approximate optimum temperature of $48{ }^{\circ} \mathrm{C}$ (Fig. 6) was 

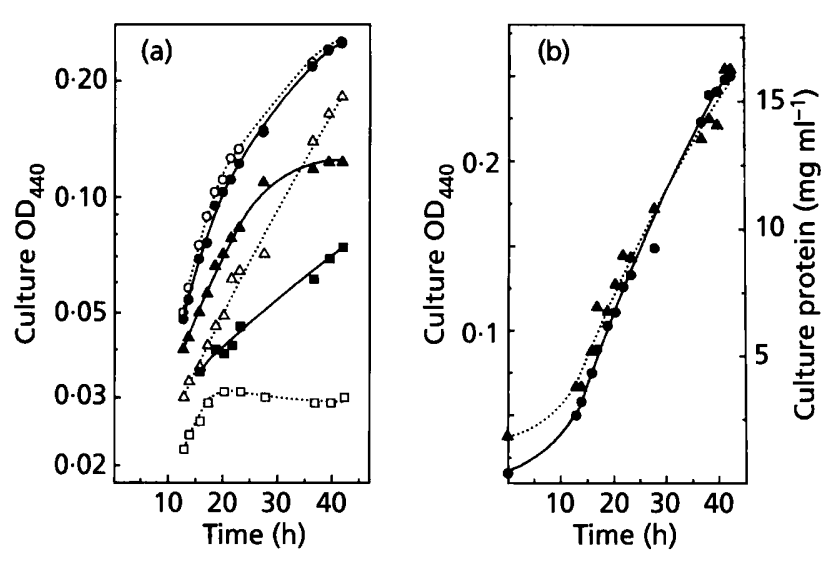

Fig. 6. Heterotrophic growth of strain ICP on yeast extract. (a) Effect of temperature $\left({ }^{\circ} \mathrm{C}\right): 34(\square), 39(\triangle), 44(0), 48(0), 53$ (A) and 57 ( $\square$ ). (b) Culture optical density (O) and protein (A) at $48^{\circ} \mathrm{C}$.

about $6 \mathrm{~h}$. Both strains were motile at about this temperature. The yield of strain ICP was reduced above $50{ }^{\circ} \mathrm{C}$. The cells became filamentous at $57^{\circ} \mathrm{C}$ (the inoculum was from a $48^{\circ} \mathrm{C}$ culture) and the little growth that occurred (Fig. 6) might not be sustainable through serial culture at this temperature.

\section{DISCUSSION}

Since strain TH3 was originally isolated (Brierley, 1978) and re-isolated (Norris \& Barr, 1985), one other moderately thermophilic, iron-oxidizing bacterium of apparently similar appearance has been described, but not maintained in a culture collection. Strain HTPH, originally from an Australian coal mine, was $0.4 \mu \mathrm{m}$ in width, had a tendency to form long filaments of individual cells, and had a G + C content of $68 \mathrm{~mol} \%$ (Ghauri \& Johnson, 1991). In contrast to these isolates, strain ICP did not usually grow in filaments. However, strain ICP and strain TH3 were shown to be isolates of the same species with otherwise identical morphologies, identical capacities for ferrous iron oxidation and heterotrophic growth, the same mol \% G $+\mathrm{C}$ content and essentially identical electrophoretic whole-cell protein profiles. It is proposed to name the species Acidimicrobium ferrooxidans. It is likely that, in the past, strains with the typical, single or paired cell habit of strain ICP would have been overlooked more easily than strains with the filamentous habit of TH3 or HTPH during examination of natural mixed cultures, but there is so far no evidence that this species has the widespread distribution of Sulfobacillus species in acidic environments.

Novel, autotrophic, moderately thermophilic, mineralsulphide-oxidizing bacteria were suspected of catalysing ferrous iron oxidation and consequent rapid dissolution of pyrite in an enrichment culture under air (Norris \& Owen, 1993). An enhanced $\mathrm{CO}_{2}$ concentration, in the absence of organic nutrients, was expected to be required for equivalent activity of previously described mineralsulphide-oxidizing Sulfobacillus species. However, the capacity of strain ICP from the enrichment culture to fix $\mathrm{CO}_{2}$, when this was present at its normal atmospheric concentration, appeared sufficient to promote more extensive ferrous iron oxidation in mixed culture with Sulfobacillus species than occurred in pure cultures under air. The greater efficiency of strain ICP in obtaining $\mathrm{CO}_{2}$ from air derived from possession of a $\mathrm{CO}_{2}$ uptake system that was induced when $\mathrm{CO}_{2}$ was limiting, while no comparable system was found in $S$. thermosulfidooxidans (D. A. Clark \& P. R. Norris, unpublished results). The release of fixed carbon from strain ICP presumably supported mixotrophic growth of Sulfobacillus species in these mixed cultures. The different relative benefit of glucose to growth of strains NAL (S. acidophilus) and LM1 (S. thermosulfidooxidans) oxidizing ferrous iron under air (Fig. 4) was similar to that seen with other strains of these two species, strains ALV and BC1, respectively (Wood \& Kelly, 1983). The nature of the organic material provided by strain ICP for mixotrophic growth of Sulfobacillus species is not known, but it was equally effective with both species. It has been noted previously that cell leakage or autolysis products present in culture filtrate of autotrophically grown Thiobacillus ferrooxidans were sufficient to support growth of $S$. thermosulfidooxidans (strain TH1) and strain TH3 on ferrous iron (Norris et al., 1980).

The contribution of Sulfobacillus species to more extensive ferrous iron oxidation in mixed cultures with strain ICP under air probably derived from their greater tolerance of ferric iron. Iron oxidation kinetic studies with strain ICP and $S$. thermosulfidooxidans (strain BC1) that were grown autotrophically showed the latter was less inhibited by the ferric iron end-product of substrate oxidation (D. A. Clark \& P. R. Norris, unpublished results). This was probably reflected in the relatively short phase of rapid ferrous iron oxidation in cultures of strain ICP in comparison to an extended phase of rapid oxidation in $\mathrm{CO}_{2}$-supplemented cultures of Sulfobacillus species (Fig. $3)$.

The potential advantage of using a mixed culture containing strain ICP or TH3 for mineral processing would depend on whether $\mathrm{CO}_{2}$ was limiting the bacterial activity. This might not be the case if the ore or mineral concentrate being treated contained carbonate, or if limestone was used to neutralize excess acid produced from sulphide oxidation. Preliminary work with pyrite oxidation in bioreactors using the enrichment culture from which strain ICP was isolated has shown that the relative proportions of strain ICP and Sulfobacillus species changed rapidly in response to switching culture aeration between air and $\mathrm{CO}_{2}$-supplemented air, with a significant increase in the Sulfobacillus species numbers following the supplementation. The rate of pyrite oxidation did not appear to change significantly (D. A. Clark \& P. R. Norris, unpublished results). Growth of strain ICP in pure culture on pyrite was very poor, however, so further work is required with mineral sulphides in order to demonstrate a similar relationship with Sulfobacillus species in mixed culture to that seen when ferrous iron was the substrate.

The capacity of strains ICP and TH3 to grow on sulphur also requires investigation. As estimated by the change in 
medium acidity during growth on an iron-copper sulphide (chalcopyrite), the original isolate of strain TH3 did not oxidize, or oxidized only very poorly, sulphide or sulphur in comparison to the activity of $S$. thermosulfidooxidans (strain TH1) and T. ferrooxidans during equivalent mineral dissolution (Norris et al., 1980). However, the newer isolate of strain TH3 did not show a similar deficiency of acid production (P. R. Norris, unpublished results). Acidification of the medium occurred during growth of strains TH3 and ICP in medium containing yeast extract and sulphur but was weak in comparison with that produced by Sulfobacillus species (Norris et al., 1996), and remains to be quantified.

\section{Description of Acidimicrobium ferrooxidans gen. nov., sp. nov.}

Acidimicrobium (a.ci.di.mi.cro'bi.um) gen. nov. ML n. acidum acid, L. masc. adj. acidus acid; Gr. adj. micros small; Gr. masc. n. bios life; ML neuter n. Acidimicrobium, referring to a bacterium from acidic environments. ferrooxidans (fer.ro.ox'i.dans) sp. nov. L n. ferrum iron; ML v. oxido oxidize; ML part. adj. ferrooxidans ironoxidizing.

Thermotolerant or moderately thermophilic, acidophilic bacterium. Gram-positive rods, $0.35-0.4 \times 1-1.5 \mu \mathrm{m}$, which may be in filaments of variable length. Optimum growth at $45-50{ }^{\circ} \mathrm{C}$ and approximately $\mathrm{pH} 2$. Autotrophic growth on ferrous iron. Heterotrophic growth on yeast extract, during which cells are motile. Chromosomal DNA base composition 67-68.5 mol \% G +C. Found in warm, acidic, iron-, sulphur- or mineral-sulphide-rich environments. Type strain: strain ICP (German Collection of Micro-organisms, DSM 10331).

\section{ACKNOWLEDGEMENTS}

This work was supported by a SERC Biotechnology Directorate CASE studentship (D. A.C.) with Shell Research Ltd, Sittingbourne.

\section{REFERENCES}

Brierley, J. A. (1978). Thermophilic iron-oxidizing bacteria found in copper leaching dumps. Appl Environ Microbiol 36, 523-52.5.

Ghauri, M. A. \& Johnson, D. B. (1991). Physiological diversity amongst some moderately thermophilic iron-oxidising bacteria. FEMS Microbiol Ecol 85, 327-334.
Golovacheva, R. S. \& Karavaiko, G. I. (1979). Sulfobacillus - a new genus of spore-forming thermophilic bacteria. Microbiology (English translation of Mikrobiologiya) 48, 658-665.

Harrison, A. P., Jr (1986). Characteristics of Thiobacillus ferrooxidans and other iron-oxidizing species, with emphasis on nucleic acid analyses. Biotechnol Appl Biochem 8, 249-257.

Johnson, D. B. \& McGinness, S. (1991). A highly efficient and universal solid medium for growing mesophilic and moderately thermophilic iron-oxidizing, acidophilic bacteria. I Microbiol Methods 13, 113-122.

Lane, D. J., Harrison, A. P., Jr, Stahl, D., Pace, B., Giovannoni, S. J., Olsen, G. J. \& Pace, N. R. (1992). Evolutionary relationships among sulfur- and iron-oxidizing eubacteria. I Bacteriol 174, 269-278.

Karavaiko, G. I., Golovacheva, R. S., Pivovarova, T. A., Tzaplina, I. A. and Vartanyan, N. S. (1988). Thermophilic bacteria of the genus Sulfobacillus. In Biobydrometallurgy, Proceedings of the International Symposium, pp. 29 41. Edited by P. R. Norris \& D. P. Kelly. Kew: Science and Technology Letters.

Marsh, R. M. \& Norris, P. R. (1983). The isolation of some thermophilic, autotrophic iron- and sulphur-oxidizing bacteria. FEMS Microbiol Lett 17, 311-315.

Norris, P. R. (1989). Factors affecting bacterial mineral oxidation: the example of carbon dioxide in the context of bacterial diversity. In Biobydrometallurgy 1989, pp. 3-14. Edited by J. Salley, R. G. L. McCready \& P. L. Wichlacz. Ottawa: Canmet.

Norris, P. R. \& Barr, D. W. (1985). Growth and iron oxidation by acidophilic moderate thermophiles. FEMS Microbiol Lett 28, 221-224.

Norris, P. R. \& Owen, J. P. (1993). Mineral sulphide oxidation by enrichment cultures of novel thermoacidophilic bacteria. FEMS Microbiol Rev 11, 51-56.

Norris, P. R., Brierley, J. A. \& Kelly, D. P. (1980). Physiological characteristics of two facultatively thermophilic mineral-oxidising bacteria. FEMS Microbiol Lett 7, 119-122.

Norris, P. R., Clark, D. A., Owen, J. P. \& Waterhouse, S. (1996). Characteristics of Sulfobacillus acidophilus sp. nov. and other moderately thermophilic mineral-sulphide-oxidizing bacteria. Microbiology 142, 775-783.

Pertoft, H., Laurent, T. C., Låås, T. \& Kågedal, L. (1978). Density gradients prepared from colloidal silica particles coated by polyvinylpyrrolidone (Percoll). Anal Biochem 88, 271-282.

Wood, A. P. \& Kelly, D. P. (1983). Autotrophic and mixotrophic growth of three thermoacidophilic iron-oxidizing bacteria. FEMS Microbiol Lett 20, 107-112.

Received 15 August 1995; revised 20 November 1995; accepted 30 November 1995. 